\title{
BMJ Open Exposure to organisational injustice and serious psychological distress: longitudinal analysis of details of exposure from a private Japanese company
}

\author{
Toshio Hayashi, ${ }^{\ominus}$ Yuko Odagiri, Tomoko Takamiya, Hiroyuki Kikuchi, \\ Noritoshi Fukushima, Shigeru Inoue
}

To cite: Hayashi T, Odagiri Y, Takamiya T, et al. Exposure to organisational injustice and serious psychological distress: longitudinal analysis of details of exposure from a private Japanese company. BMJ Open 2019;9:e029556. doi:10.1136/ bmjopen-2019-029556

- Prepublication history for this paper is available online. To view these files, please visit the journal online (http://dx.doi. org/10.1136/bmjopen-2019029556).

Received 01 February 2019 Revised 11 September 2019 Accepted 12 September 2019

Check for updates

(C) Author(s) (or their employer(s)) 2019. Re-use permitted under CC BY-NC. No commercial re-use. See rights and permissions. Published by BMJ.

Department of Preventive Medicine and Public Health, Tokyo Medical University, Shinjuku-ku, Japan

Correspondence to Dr Toshio Hayashi; chamuo@tokyo-med.ac.jp

\section{ABSTRACT}

Objectives Studies have shown that organisational injustice (OIJ) is associated with mental disorders. However, there is little research regarding details on OIJ exposure. We examined the effect of OIJ on serious psychological distress (SPD) by considering the exposure frequency, the exposure duration and the OlJ-free period after the disappearance of exposure.

Methods We used a prospective cohort design. OIJ exposure was assessed three times with 1-year intervals between assessments, and the subjects were grouped according to the exposure histories. The outcome assessment for SPD by scores of 13 or higher on the K6 questionnaire was carried out 3 years after the baseline scores were obtained. Participants were all full-time regular employees of one office of a manufacturing company in Japan. Participants who were being treated for mental disorders, those with SPD and those with missing data on the $\mathrm{K} 6$ questionnaire in the baseline survey were excluded from the prospective cohort. Self-reported questionnaire data from 1087 employees who participated in all surveys and answered all questions were analysed. Logistic regression analysis was used to explore the effect of OIJ on SPD.

Results SPD developed in 35 participants. Frequent OIJ exposure was associated with a higher risk for SPD ( $p$ for trend=0.002). Of the 1087 participants, $319(29.3 \%)$ experienced a change in OIJ exposure at least once, and $8.6 \%$ of subjects experienced such a change twice. These changes in OIJ exposure were more strongly related to SPD than was the frequency of OIJ exposure.

Conclusions OIJ was associated with SPD onset particularly when the workers were more frequently exposed to it. Moreover, frequent changes in the OIJ exposure were associated with a higher risk for SPD. Because OIJ exposure can change in a relatively short time, considering exposure histories may provide useful information for preventing mental disorders.

\section{INTRODUCTION}

Organisational justice $(\mathrm{OJ})$ is a notable psychosocial factor in the workplace. In the historical review of justice research, the

\section{Strengths and limitations of this study}

- This study had a longitudinal design that comprised multiple surveys and had a high rate of response $(\geq 85 \%)$.

- This study examined the influence of organisational injustice (OIJ) on serious psychological distress by considering exposure details such as the effect of exposure frequency, exposure duration and OIJ-free period after the disappearance of exposure.

- As self-administered questionnaires were used to assess the both exposure and outcome, there may exist the possibility of reporting bias.

- The study sample comprised full-time and regular employees of a large private company; therefore, the generalisability to other type of workers is uncertain.

first and most acknowledged form of justice is distributive justice, an assessment of the fairness of decision-making outcomes. The second is procedure justice, an assessment of the fairness of the procedures used to determine these outcomes. Studies exploring procedure justice have found that perceptions of procedure justice are often influenced by interpersonal elements, including interpersonal justice and informational justice. ${ }^{1}$ Because these justice components are highly correlated, it is recommended to treat them as latent variables, without examining the unique effect of each component. ${ }^{2}$

Organisational injustice (OIJ) refers to a situation in which an employee perceives the organisation's decision-making outcome and/or processes to be unfair, and/or feels to be treated unfair by supervisor. A number of studies have revealed that OIJ is associated with common mental disorders. ${ }^{3-5}$ Despite the wealth of evidence, most studies have not evaluated exposure details, such as 
the exposure frequency, the exposure duration and the exposure-free period after disappearance of exposure. Therefore, the length of exposure that increases the risk of common mental disorders and the length of exposure-free periods to decrease the risk are unclear. ${ }^{3}$

Conducting multiple exposure assessments would be an effective strategy to evaluate exposure histories. However, only a limited number of studies have measured multiple exposures. Theorell et al ${ }^{4}$ systematically reviewed studies of work environment and depressive symptoms; of the 59 articles judged to be of high or medium-tohigh scientific quality, only eight involved more than two assessments of exposure times, and of these eight, three documented associations between job strain and depressive symptoms. ${ }^{6-8}$ However, other psychosocial factors, such as OIJ, were not examined. Furthermore, no researchers have examined how long it takes for risk level to return to the pre-exposure state after cessation of exposure. Niedhammer and Chastang ${ }^{9}$ reported that the effects of psychosocial work risk factors (ie, high psychological demands, poor social support) on mental health may be reduced 2 years after the cessation of exposure. However, that study retrospectively assessed the exposure of psychosocial work factors. Therefore, prospective studies are needed to examine the effect of exposure-free period after the disappearance of exposure.

Several studies have revealed that favourable changes in OJ have desirable consequences on health outcomes and vice versa, ${ }^{10-12}$ that optimal OJ promotes recovery from stress reactions such as sleep disorders, ${ }^{12} 13$ and that OJ can be modified by intervention. ${ }^{14-17}$ Nevertheless, to our knowledge, the relationship between OIJ and mental disorders has not yet been studied with regard to the effects of exposure duration, frequency of change in OIJ exposure and the OIJ-free period after the disappearance of exposure.

Our objective was, therefore, to examine how OIJ exposure influenced the risk for the onset of serious psychological distress (SPD) considering the exposure details. First, we examined the relationship between OIJ exposure frequency and SPD to explore the dose-response associations. Second, we examined the effect of OIJ exposure details such as exposure duration, frequency of change in OIJ exposure and the OIJ-free period after the disappearance of exposure on SPD.

\section{METHOD}

\section{Participants and data collection}

We used the panel survey data. Participants were all fulltime regular employees at one office of a manufacturing company. The baseline survey was conducted in November 2012 (phase 1), and the follow-up surveys were conducted in November 2013 (phase 2), November 2014 (phase 3) and November 2015 (phase 4). The first to fourth surveys were sent to 2657, 25873084 and 3171 workers, respectively. The numbers of respondents to these surveys were 2475 (93.2\% response rate), 2481 (95.9\%), 2943 (95.4\%) and 2814 (88.7\%), respectively. After we excluded participants under treatment for mental disorders $(n=103)$, those with serious mental illness $(n=124)$, and those with data missing on the K6 questionnaire in the phase 1 (baseline) survey ( $\mathrm{n}=64), 2199$ participants were eligible for the prospective cohort study. In the follow-up surveys, 1869 employees responded in phase $2(85.0 \%$ of the eligible participants), 1692 employees responded in phase $3(76.9 \%)$ and 1528 employees responded in phase $4(69.5 \%)$. Of the eligible respondents, $1400(63.7 \%)$ participated in all four surveys. After exclusion of those with missing variables, 1087 employees $(49.4 \%$ of the eligible participants at baseline) were included in the analysis. A flowchart of the participant sampling is shown in figure 1 . The phases 1-3 surveys were exposure assessments. We conducted the surveys at 1-year intervals to align the environmental factors (eg, seasonal factors, such as sunlight hours) and business factors, such as financial period. The phase 4 surveys, conducted 3 years after the baseline survey, were used for outcome assessment.

A self-administered questionnaire was used in the surveys. About $90 \%$ of the subjects responded on their own computers through the use of a security-protected intranet; the other $10 \%$ of data were obtained by paper questionnaires collected in a sealed envelope. The questionnaire was designed so that all the participants were required to read the instructions and explanation for the survey beforehand and gave their responses voluntarily.

\section{Measurement}

Organisational justice

OJ was assessed using a Colquitt's OJ measure. ${ }^{18}{ }^{19} \mathrm{It}$ includes 20 items and 4 scale dimensions: distributive, procedural, interpersonal and informational justice. All items were assessed on a 5-point Likert scale ranging from 1 to 5 , in which a high score indicated high OJ. In this sample, Cronbach's $\alpha$ coefficients were 0.96 in phase 1 , 0.95 in phase 2 and 0.96 in phase 3.

\section{Organisational injustice}

Low OJ is defined as OIJ in the present study. The assessment of OIJ exposure varies across studies. For example, Theorell's systematic review involved five high-quality or medium-to-high-quality studies that examined OJ, and among these, two studies documented the association between perceived OIJ and depressive symptoms. In one study, participants in the lowest tertiles were defined as having OIJ exposure, ${ }^{20}$ and the other study defined OIJ exposure to be in the lowest quartile. ${ }^{21}$ In the present study, we calculated the justice score of all participants and defined participants with scores in the lowest quartile as having OIJ exposure.

\section{OIJ exposure details}

We classified the participants into eight groups in accordance with the history of OIJ exposure from phases 1-3. We evaluated the frequency of exposure and the frequency of exposure change in the first three assessments. All 


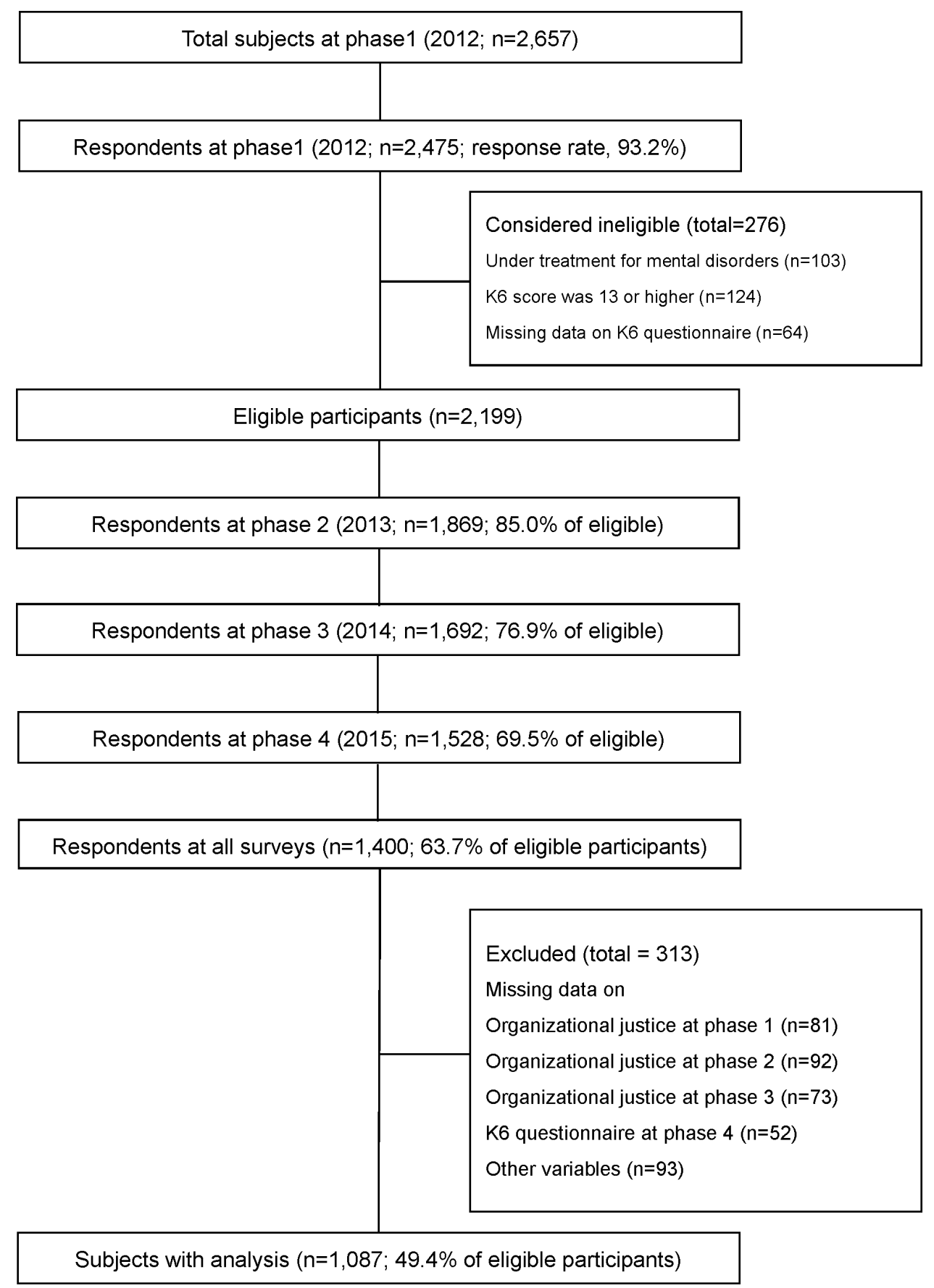

Figure 1 Flow chart of numbers of participants in the study.

participants were classified as having had no OIJ exposure (exposure frequency $=0$ ), exposure one or two times and continuous exposure (exposure frequency=3). Participants were also classified into 0-2 regarding the frequencies of OIJ exposure change. The duration, that is, OIJ exposure duration and the OIJ-free period after the disappearance of exposure, was evaluated based on the assumption that the exposure condition continued unless the exposure status changed in a subsequent survey during 3 years from phase 1 to phase 4 . Table 1 shows the details of OIJ exposure.

\section{Serious psychological distress}

To measure SPD, we administered the K6 questionnaire. $^{22-24}$ The K6 questionnaire has high validity and reliability and is a valuable tool for screening psychological distress and clinical psychiatric disorders such as depression and anxiety disorders. Its six items were assessed with a 5-point Likert scale ranging from 0 to 4 , in which a high score represented high psychological distress. In this sample, Cronbach's $\alpha$ coefficients were 0.83 in phase 1 and 0.90 in phase 4 . SPD was indicated by a K6 score of 13 or higher, in accordance with previous study, ${ }^{25}$ and this cut-off point has been reported to be eligible by a questionnaire survey conducted in Japan. ${ }^{26}$

\section{Other characteristics}

Questions pertained to sex, age, marital status, type of occupation, working conditions (shift work/other), 
Table 1 Description of organisational injustice (OIJ) exposure details

\begin{tabular}{|c|c|c|c|c|c|c|c|}
\hline Group no & \multicolumn{3}{|c|}{ OIJ exposure } & $\begin{array}{l}\text { Exposure } \\
\text { frequency }\end{array}$ & $\begin{array}{l}\text { Frequency } \\
\text { of exposure } \\
\text { change }\end{array}$ & $\begin{array}{l}\text { Exposure } \\
\text { duration }\end{array}$ & $\begin{array}{l}\text { OlJ-free period after } \\
\text { the disappearance ot } \\
\text { exposure }\end{array}$ \\
\hline 1 & - & - & - & 0 & 0 & None & - \\
\hline 2 & + & - & - & 1 & 1 & 1 year or less & 2 years or less \\
\hline 3 & - & + & - & 1 & 2 & 1 year or less & - \\
\hline 6 & + & - & + & 2 & 2 & $1-2$ years & - \\
\hline 7 & - & + & + & 2 & 1 & $1-2$ years & - \\
\hline 8 & + & + & + & 3 & 0 & $2-3$ years & - \\
\hline
\end{tabular}

occupational status (manager/deputy manager/regular employee), overtime work hours per month (less than 20, 20-45 and 45-80 and more than 80 hours), smoking status (current smoker or non-smoker), alcohol consumption frequency (never or occasionally vs almost every day) and regular physical activity (engaging in more than half an hour of exercise two times or more per week or not exercising at this frequency). Current mental disorders (under medical treatment or not) were asked at phase 1 .

\section{Statistical analysis}

The differences in the baseline variables between the subjects who completed all four surveys and those who dropped out of the study were investigated with a t-test and Fisher's exact test.

We constructed a cross-lagged structural equation model between OJ (phase 1 and phase 3) and distress (phase 1 and phase 4 ) to explore the direction of the association. $^{27}$

First, we analysed the association between frequency of exposure to OIJ and the presence of SPD. We conducted logistic regression analysis in which exposure frequency was the independent variable, data from participants who were never exposed to OIJ were used for reference, and the presence of SPD at phase 4 was the dependent variable. We also conducted a sensitivity analysis wherein we changed the definition of OIJ exposure (ie, scores in the median and tertile reflected OIJ exposure) to confirm the relationships.

Second, we analysed the effects of OIJ exposure on SPD with regard to the duration of exposure and the exposure-free period after the disappearance of exposure. We conducted logistic regression analysis in which OIJ exposure group was the independent variable and the presence of SPD at follow-up (phase 4) was the dependent variable. To examine the effects of exposure duration and changes in exposure, we used the data from the participants who were never exposed to OIJ for reference. Furthermore, we used data from participants who were continuously exposed to OIJ for reference when we examined the effect of cessation of exposure.
Results of logistic regression analysis are presented as ORs and 95\% CIs adjusted for sex, age, occupational status, overtime work, smoking status, drinking frequency and regular physical activity. Statistical significance was set at $\mathrm{p}<0.05$. SPSS V.20 and STATA V.15 statistical software were used for the analysis.

\section{Patient and public involvement}

No participants were involved in developing research questions, outcome measures and the overall study design. The results of this study will not be directly disseminated to study participants.

\section{RESULTS}

In comparing baseline characteristics of respondents with those of drop-outs, we found that drop-outs were more likely to be of high occupational status, less likely to be manual workers, and more likely to have regular physical activity. There were no statistically significant differences in other characteristics. Baseline characteristics of study subjects are listed in table 2 . The mean age of the subjects was $40.9(\mathrm{SD}=8.7)$ years. The majority of subjects were men $(90.7 \%)$, were engaged in technical work $(58.1 \%)$ and worked an extra 20-45 hours per month (52.2\%). In phase 4,35 participants $(3.2 \%$ of subjects with analysis) had SPD.

The results of the cross-lagged analysis showed that the direction of the association between OJ and distress was from earlier OJ to later distress. The model that incorporated the path from earlier OJ to later distress (forward model: $\chi^{2}=584.80$, standardized root mean square residual $(\mathrm{SRMR})=0.049$, comparative fit index $(\mathrm{CFI})=0.91$ and Tucker-Lewis index $(\mathrm{TLI})=0.88)$ was found to be a better fit than the model that incorporated the path from earlier distress to later OJ (reverse model: $\chi^{2}=589.00, \quad \mathrm{SRMR}=0.054, \mathrm{CFI}=0.91$ and $\left.\mathrm{TLI}=0.88\right)$. The association between earlier OJ to later distress was significant (coefficient $=-0.06 ; \mathrm{p}<0.05 ; \mathrm{z}=-2.10$ ). In contrast, the association from earlier distress to later OJ was not significant $($ coefficient $=-0.01 ; \mathrm{p}=0.69 ; \mathrm{z}=-0.41)$. 
Table 2 Baseline characteristics of subjects

\begin{tabular}{|c|c|c|c|}
\hline \multirow{2}{*}{ Variables } & & \multicolumn{2}{|c|}{$n=1087$} \\
\hline & & \multirow{2}{*}{$\begin{array}{l}\mathbf{n} \\
986\end{array}$} & \multirow{2}{*}{$\begin{array}{l}\% \\
90.7\end{array}$} \\
\hline \multirow[t]{2}{*}{ Sex (phase 1) } & Men & & \\
\hline & Women & 101 & 9.3 \\
\hline Age (years) (phase 1) & Mean (SD) & \multicolumn{2}{|c|}{$40.9(8.7)$} \\
\hline \multirow{5}{*}{$\begin{array}{l}\text { Type of occupation } \\
\text { (phase1) }\end{array}$} & Technician & 632 & 58.1 \\
\hline & Manual worker & 196 & 18.0 \\
\hline & Manager & 101 & 9.3 \\
\hline & Clerk & 131 & 12.1 \\
\hline & Other & 27 & 2.4 \\
\hline \multirow[t]{3}{*}{$\begin{array}{l}\text { Occupational status } \\
\text { (phase 1) }\end{array}$} & $\begin{array}{l}\text { Managerial } \\
\text { position }\end{array}$ & 218 & 20.1 \\
\hline & Deputy manager & 377 & 34.7 \\
\hline & Regular employee & 492 & 45.3 \\
\hline \multirow{3}{*}{$\begin{array}{l}\text { Overtime work } \\
\text { (hours/month) (phase } \\
\text { 1) }\end{array}$} & $<20$ & 298 & 27.4 \\
\hline & $\leqq 20$ to $<45$ & 567 & 52.2 \\
\hline & $\leqq 45$ & 222 & 20.5 \\
\hline \multirow{5}{*}{$\begin{array}{l}\text { Sleeping hours } \\
\text { (hours/day) (phase 1) }\end{array}$} & $<4$ & 27 & 2.5 \\
\hline & $\leqq 4$ to $<5$ & 186 & 17.1 \\
\hline & $\leqq 5$ to $<6$ & 529 & 48.7 \\
\hline & $\leqq 6$ to $<7$ & 296 & 27.2 \\
\hline & $\leqq 7$ & 49 & 4.5 \\
\hline \multicolumn{2}{|l|}{$\begin{array}{l}\text { Current smoker } \\
\text { (phase1) }\end{array}$} & 319 & 29.3 \\
\hline \multicolumn{2}{|c|}{$\begin{array}{l}\text { Regular drinker (almost every day) } \\
\text { (phase 1) }\end{array}$} & 327 & 30.1 \\
\hline \multicolumn{2}{|l|}{$\begin{array}{l}\text { Regularly physically } \\
\text { active (phase1) }\end{array}$} & 196 & 18.0 \\
\hline K6 score (phase 4) & Mean(SD) & \multicolumn{2}{|c|}{$3.1(3.1)$} \\
\hline $\begin{array}{l}\text { Serious } \\
\text { psychological } \\
\text { distress (phase4) }\end{array}$ & K6 score $\geqq 13$ & 35 & 3.2 \\
\hline
\end{tabular}

Table 3 lists the results of logistic regression analysis to explore the association between frequency of exposure to OIJ and SPD. The results of the logistic regression analysis showed that frequent OIJ exposure was associated with a higher risk for SPD (for trend, $\mathrm{p}=0.008$ ) after adjustment for sex, age, occupational status, overtime work, smoking status, drinking frequency and regular physical activity, these relationships remained significant. A sensitivity analysis wherein we changed the definition of OIJ (ie, scores in the median and tertile reflected OIJ exposure) revealed that frequent OIJ exposure is also associated with higher risk of distress.

Table 4 describes the subject groups according to the OIJ exposure histories. There were 630 subjects who were never exposed to OIJ (group 1) and 138 subjects who were continuously (ie, for longer than 2 years) exposed to OIJ (group 8). Of the other subjects, 319 (29.3\%) experienced changes in OIJ exposure at least once during the observational period (groups 2-7); 93 (8.6\%) experienced such changes twice, either (1) from no OIJ exposure to OIJ exposure and then back or (2) vice versa (groups 3 and 6).

In the logistic regression analysis in which data from the participants who experienced no exposure to OIJ (group 1) were used for reference, results showed that participants exposed to OIJ continuously (group 8) had the highest risk for SPD (adjusted OR 4.46; 95\% CI 1.76 to 11.30). There were no significant relationships between amount of exposure and psychological distress for participants who were newly exposed to OIJ (ie, exposure period was less than 2 years) during observation (groups 4 and 7). Of interest is that participants who experienced changes in exposure to OIJ twice-from no OIJ exposure to OIJ exposure and back, or vice versa-showed a higher risk for SPD (groups 3 and 6) that was significant or marginally significant. Participants whose exposure to OIJ improved (groups 2 and 5) showed no significant relationship between OIJ exposure and psychological distress in comparison with those continuously exposed to OIJ (group 8).

\section{DISCUSSION}

The main finding of this study is that the relationship between OIJ exposure frequency and SPD was observed in the cohort design. Continuous OIJ exposure conferred

\begin{tabular}{|c|c|c|c|c|c|c|}
\hline Exposure frequency & n (\%) & Prevalence (n) & Unadjusted OR $(95 \% \mathrm{Cl})$ & $P$ value & Adjusted OR $(95 \% \mathrm{Cl}) \dagger$ & $P$ value \\
\hline \multicolumn{7}{|l|}{ Organisational injustice } \\
\hline 1 & $184(16.9)$ & $4.3(8)$ & 2.16 (0.88 to 5.29$)$ & 0.093 & 2.36 (0.95 to 5.85$)$ & 0.065 \\
\hline 2 & $135(12.4)$ & $3.7(5)$ & $1.83(0.64$ to 5.21$)$ & 0.261 & $1.97(0.68$ to 5.71$)$ & 0.212 \\
\hline$P$ for trend & & & & 0.008 & & 0.002 \\
\hline
\end{tabular}

*Serious psychological distress is indicated by a K6 score of 13 or higher. Of the participants, 35 (3.2\%) had serious psychological distress at phase 4.

†Adjusted for sex, age, occupational status, overtime work, smoking status, drinking frequency and regular physical activity. 


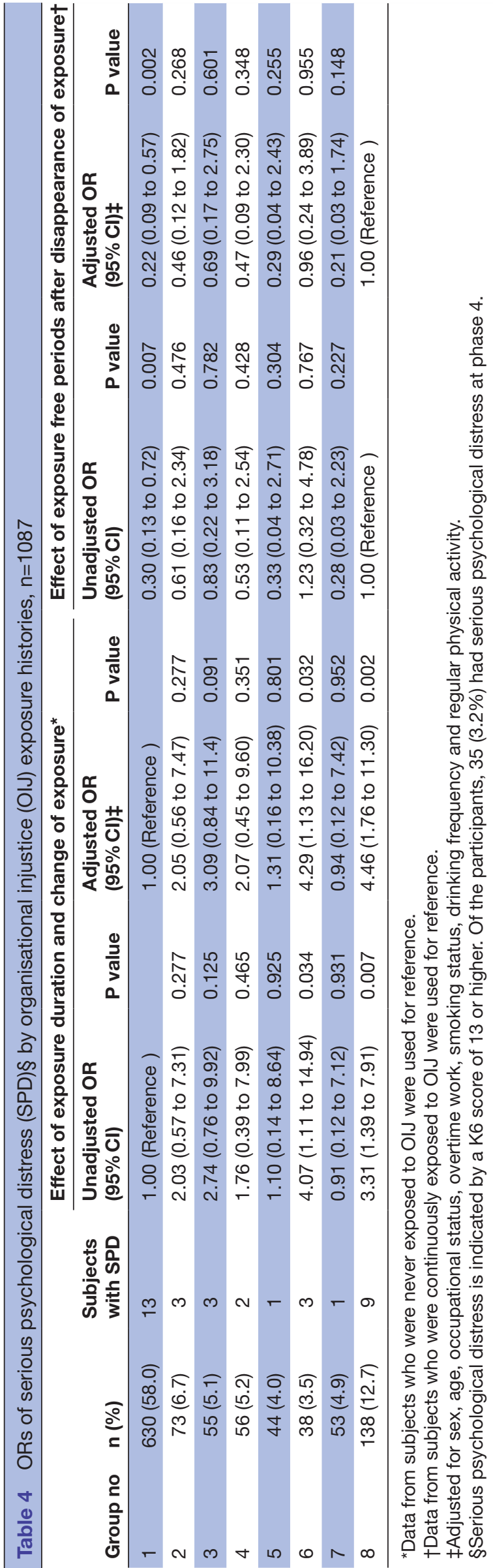

a higher risk of SPD onset; however, the participants who were newly exposed to OIJ during observation showed no significant relationships. Participants who experienced OIJ improvement during observation showed no significant relationship in comparison with those who were continuously exposed to OIJ. Experiencing OIJ changes more frequently increased the risk of SPD.

Previous studies showed that the longer the duration of job strain, the higher the risk of depression. ${ }^{68}$ Our results were in agreement with those findings. We suggest that such associations also exist between exposure to OIJ and the presence of mental health disorders.

Our results showed that the participants continuously exposed to OIJ (group 8) had a significantly higher risk for SPD than did participants who were never exposed to OIJ. However, participants newly exposed to OIJ during observation (groups 4 and 7) did not evince significantly higher risk for SPD. Although our findings were limited, we suggest that continuous exposure to OIJ for more than 2 years might cause the risk for SPD onset to increase significantly.

With regard to recovery from SPD, we found no significant relationships in the participants whose exposure to OIJ was eliminated (ie, OIJ exposure-free period was less than 2 years: groups 2 and 5), which suggests that exposure-free periods must be longer than 2 years in order to attenuate the risk of SPD onset. This result is consistent with those of the investigation (by retrospective interview) of the associations between psychosocial work risk factors (high psychological demands, poor social support) and depressive symptoms. ${ }^{9}$ Furthermore, this result provides new information because, to our knowledge, no researchers had previously used a prospective study design to examine the duration of psychological distress after cessation of psychosocial job strain.

With regard to the exposure histories, 319 subjects (29.3\%) experienced changes in exposure to OIJ in the 2 years after baseline measurement. Previous studies also showed that about $40 \%$ of subjects experienced changes in exposure to OIJ during a 5-year period. ${ }^{10}{ }^{11}$ We suggest that the OIJ exposure could be changed in a relatively short period.

In comparisons of subjects who were exposed to OIJ at the same frequency (ie, groups 5-7), we found that those who experienced changes in exposure twice showed a higher risk for SPD than did those who experienced only one such change. This result was interesting because the subjects who experienced only adverse change (group 5) showed a lower risk for SPD than those who experienced both adverse change and favourable change (group 6). It is presumed that the work environments changed when exposure to OIJ changed. When a work environment changes, workers must adapt to the new environment. Therefore, even when the changes were favourable, frequent changes in a relatively short period cause the burden of readjustment and might increase the risk for SPD. Several studies have revealed that OJ is modifiable by intervention. ${ }^{14-17}$ However, the effect of long-term 
continuous change has not been examined. The duration of the changes must be researched further.

The strengths of this study are the longitudinal study design and a high rate of response (85\% or more) to multiple surveys. However, this study also had several limitations. First, we did not obtain the information about physical disorders that may have influenced mental disorders. Although we excluded participants with SPD as well as those who reported treatment for mental disorder at baseline survey, we could not examine the physical disorders could affect mental disorders.

Second, we examined only work-related factors. Life events outside work (eg, divorced, death of or severe illness in spouses or in other family members) might also be associated with mental disorders.

Third, this study sample consisted of regular employees of a large private company, mainly men and white collar. The findings cannot be generalised to other types of workers such as temporary workers, women and bluecollar workers. However, the effect of OIJ is more notable in white-collar employees than in blue-collar employees, ${ }^{28}$ thus, it might be useful to examine the effect of OIJ in white-collar dominant populations.

Fourth, all survey items were self-reported and not measured objectively. The possibility of reporting bias must be kept in mind.

Fifth, we could not assess the OIJ exposure before observation periods or after phase 3 . Therefore, before or after the observation period, we cannot rule out the possibility of OIJ exposure changes, for example, the non-exposure group might have been exposed or the continuous exposure group might not have had the exposure.

Sixth, although we excluded the SPD cases and those under treatment for mental disorders at baseline survey, those who newly developed SPD during the observation period might poorly respond to subsequent surveys and thus reduced the number of SPD cases at phase 4 .

In conclusion, this study showed an association between the frequency of OIJ exposure and SPD. Continuous OIJ exposure might have to last more than 2 years to significantly increase the risk for SPD. In addition, frequent changes in $\mathrm{OIJ}$ exposure are associated with a higher risk for SPD. Because the OIJ exposure could be changed in a relatively short time, the exposure histories must be considered in examinations of the effect of OIJ on mental disorders.

Contributors $\mathrm{TH}$, the corresponding author, was the primary contributor to study design, data collection, statistical analyses and manuscript writing. Y0 and TT helped in conceiving the study, analysing the data and drafting the manuscript. HK, $\mathrm{NF}$ and SI provided critical review and contributed to the completion of the draft. All authors read and approved the final manuscript.

Funding The authors have not declared a specific grant for this research from any funding agency in the public, commercial or not-for-profit sectors.

Competing interests None declared.

Patient consent for publication Not required.

Ethics approval The study was carried out with the approval of the health and safety committee of the office. The ethics committee of Tokyo Medical University approved the study procedure (approval number: 3614 ).
Provenance and peer review Not commissioned; externally peer reviewed.

Data availability statement № additional data are available.

Open access This is an open access article distributed in accordance with the Creative Commons Attribution Non Commercial (CC BY-NC 4.0) license, which permits others to distribute, remix, adapt, build upon this work non-commercially, and license their derivative works on different terms, provided the original work is properly cited, appropriate credit is given, any changes made indicated, and the use is non-commercial. See: http://creativecommons.org/licenses/by-nc/4.0/.

\section{REFERENCES}

1. Colquitt JA, Greenberg J. What is organizational justice? A historical overview. In: Handbook of organizational justice. Mahwah NJ: Lawrence Erlbaum Associates Inc, 2005: 3-56.

2. Colquitt JA, Rodelland JB. Measuring justice and fairness. In: Cropanzano R, Ambrose M, eds. The Oxford handbook of justice in the workplace. New York: Oxford University Press, 2015: 187-204.

3. Netterstrøm B, Conrad N, Bech P, et al. The relation between workrelated psychosocial factors and the development of depression. Epidemiol Rev 2008;30:118-32.

4. Theorell T, Hammarström A, Aronsson G, et al. A systematic review including meta-analysis of work environment and depressive symptoms. BMC Public Health 2015;15:738.

5. Harvey SB, Modini M, Joyce S, et al. Can work make you mentally ill? A systematic meta-review of work-related risk factors for common mental health problems. Occup Environ Med 2017;74:301-10.

6. de Lange AH, Taris TW, Kompier MAJ, et al. Effects of stable and changing demand-control histories on worker health. Scand J Work Environ Health 2002;28:94-108.

7. Wang J, Schmitz N, Dewa C, et al. Changes in perceived job strain and the risk of major depression: results from a population-based longitudinal study. Am J Epidemiol 2009;169:1085-91.

8. Stansfeld SA, Shipley MJ, Head J, et al. Repeated job strain and the risk of depression: longitudinal analyses from the Whitehall II study. Am J Public Health 2012;102:2360-6.

9. Niedhammer I, Chastang J-F. Psychosocial work factors and first depressive episode: retrospective results from the French national SIP survey. Int Arch Occup Environ Health 2015;88:835-47.

10. Kivimäki M, Ferrie JE, Head J, et al. Organisational justice and change in justice as predictors of employee health: the Whitehall II study. J Epidemiol Community Health 2004;58:931-7.

11. Ferrie JE, Head J, Shipley MJ, et al. Injustice at work and incidence of psychiatric morbidity: the Whitehall II study. Occup Environ Med 2006;63:443-50.

12. Lallukka T, Halonen JI, Sivertsen B, et al. Change in organizational justice as a predictor of insomnia symptoms: longitudinal study analysing observational data as a non-randomized pseudo-trial. Int $J$ Epidemiol 2017;46:1277-84.

13. Hayashi T, Odagiri Y, Takamiya T, et al. Organizational justice and insomnia: a prospective cohort study examining insomnia onset and persistence. Int Arch Occup Environ Health 2017;90:133-40.

14. Skarlicki DP, Latham GP. Increasing citizenship behavior within a labor Union: a test of organizational justice theory. J Appl Psychol 1996;81:161-9.

15. Skarlicki DP, Latham GP. Leadership training in organizational justice to increase citizenship behavior within a labor Union: a replication. Pers Psychol 1997;50:617-33.

16. Greenberg J. Losing sleep over organizational injustice: attenuating insomniac reactions to underpayment inequity with supervisory training in interactional justice. J Appl Psychol 2006;91:58-69.

17. Nakamura S, Somemura $\mathrm{H}$, Sasaki N, et al. Effect of management training in organizational justice: a randomized controlled trial. Ind Health 2016;54:263-71.

18. Colquitt JA. On the dimensionality of organizational justice: a construct validation of a measure. J Appl Psychol 2001;86:386-400.

19. Shibaoka M, Takada M, Watanabe M, et al. Development and validity of the Japanese version of the organizational justice scale. Ind Health 2010;48:66-73

20. Ylipaavalniemi J, Kivimäki M, Elovainio M, et al. Psychosocial work characteristics and incidence of newly diagnosed depression: a prospective cohort study of three different models. Soc Sci Med 2005;61:111-22.

21. Kivimäki M, Vahtera J, Elovainio M, et al. Effort-reward imbalance, procedural injustice and relational injustice as psychosocial predictors of health: complementary or redundant models? Occup Environ Med 2007;64:659-65. 
22. Kessler RC, Andrews G, Colpe LJ, et al. Short screening scales to monitor population prevalences and trends in non-specific psychological distress. Psychol Med 2002;32:959-76.

23. Furukawa TA, Kawakami N, Saitoh M, et al. The performance of the Japanese version of the K6 and K10 in the world mental health survey Japan. Int J Methods Psychiatr Res 2008;17:152-8.

24. Kessler RC, Green JG, Gruber MJ, et al. Screening for serious mental illness in the general population with the K6 screening scale: results from the who world mental health (WMH) survey initiative. Int $J$ Methods Psychiatr Res 2010;19(Suppl 1):4-22.
25. Kessler RC, Barker PR, Colpe LJ, et al. Screening for serious mental illness in the general population. Arch Gen Psychiatry 2003;60:184-9.

26. Sakurai K, Nishi A, Kondo K, et al. Screening performance of K6/K10 and other screening instruments for mood and anxiety disorders in Japan. Psychiatry Clin Neurosci 2011;65:434-41.

27. Elovainio M, Heponiemi T, Jokela M, et al. Stressful work environment and wellbeing: what comes first? J Occup Health Psychol 2015;20:289-300.

28. Herr RM, Bosch JA, Loerbroks A, et al. Three job stress models and their relationship with musculoskeletal pain in blue- and white-collar workers. J Psychosom Res 2015;79:340-7. 